\title{
Comparison of chromosome centromere topology in differentiating cells with myogenic potential
}

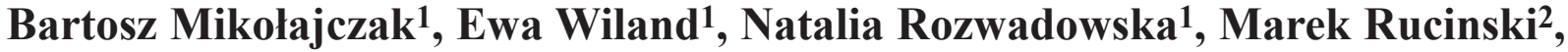 \\ Tomasz Mietkiewski², Maciej Kurpisz ${ }^{1}$
}

${ }^{1}$ Institute of Human Genetics, Polish Academy of Science, Poznań, Poland

${ }^{2}$ Traumatology and Orthopaedics Department, District Hospital of Wielkopolska, Poznań, Poland

\begin{abstract}
Chromosome territories (CT's) constitute the critical element of the intranuclear architecture. Position of these compartmentalized structures plays an important role in functioning of entire genome. Present study was to examine whether the centromeres position of chromosomes $4, \mathrm{X}$ and $\mathrm{Y}$ can be changed during differentiation from myoblasts to myotubes. Topological analysis of these centromeres was based on two-dimensional fluorescent hybridization in situ (2D-FISH). During differentiation process the majority of $\mathrm{X}$ chromosome centromeres analyzed shifted to the peripheral part of a nucleus and similar phenomenon was observed with one of the chromosome 4 centromeres. Completely different tendency was noticed when investigating the location of the chromosome Y centromeres. Centromeres of this chromosome migrated to the centre of a nucleus. The results obtained demonstrated visible changes in chromosome topology along the myogenic stem cells differentiation.
\end{abstract}

Key words: centromere, chromosome topology, FISH, human, myoblasts, myotubes

\section{Introduction}

A present knowledge on chromosome topology allows to acknowledge that chromatin organization as well as its possible alterations may exert a clear effect on the genomic transcription activity, forming characteristic epigenetic pattern for every cell type [1-3]. An intranuclear architecture is perceived as a very important regulatory element of epigenetic mechanisms. To examine the chromosome topology, different research strategies were applied so far, from examination of entire chromosomes through topology of their regions (e.g. centromeres, telomeres) to the encoding sequences. Many aspects in respect to nuclear architecture at the cell differentiation process have been so far presented [4]. Data connected with flexibility in chromosome location at the differentiation process was demonstrated in the human leukaemic K-562 cell line subjected to the interleukin-3 (IL-3) [5]. During examination of chromosome 11 and $\beta$-like globin gene location on 11p15.4 fragment it was shown that during

Correspondence: M. Kurpisz, Institute of Human Genetics, Polish Academy of Sciences, Strzeszyńska 32 Str., 60-479 Poznań; tel.: (+4861) 6579202, fax.: (+4861) 8233235, e-mail: kurpimac@man.poznan.pl the cell differentiation the studied chromosome relocated to the nuclear periphery in contrast with the $\beta$-like globin gene, which was stable even after IL-3 treatment. Pending the process of differentiation of human fat cells, [6] it was observed some regularity connected with changes in location of 12 and 16 CT's. It was then put forward a theory which says that during the cell differentiation and enlargement, chromosome territories are getting closer facilitating formation of the translocations between approaching chromosomes. Level of gene expression obviously depends on the developmental stage of the cell. Chromatin domains containing genes, which expression is essential at the particular stage, are exposed to effect of transcription factors, by moving at first to the chromosome territory, and then looping to interchromatin compartment. Such observation was made while examining Hoxb gene, concerning its expression in mouse embryonic stem cells [7]. In 2005, Wiblin et al. made interesting observations using human embryonic stem cells. They showed that chromosome 12, precisely, its short arm with genes responsible for the cell differentiation demonstrated a central localization within nucleus [8]. At this moment two completely different hypotheses were considered to explain the mechanisms responsible for chromatin rearrangements. 
According to the first one, chromosome position is determined by its connection with motionless nuclear elements. Such anchoring of chromosomes may explain chromosome immobility and stability at the cell cycle, but it does not explain non-random chromosome arrangement, unless there exists any chromosome-specific "tie-mechanism" with encoded relevant information. The alternative hypothesis postulates that, among the different nuclear mechanisms, also functions the chromosomes' arranging mechanism like a self-organization system. In this model every chromosome position is being determined by general activity of active and silent genes of particular chromosome. Probably this model, relies on the fact that the expression of determined gene regions influences the local chromatin structure, containing condense and inactive heterochromatin areas but also decondensed and highly active euchromatin. It is believed, that different chromosomes possess distinct physical properties, depending on genome activity and linear spread of active and inactive chromosome regions. This could determine the probability of interaction between chromosomes and their distribution. Chromosome clustering, especially clustering of chromosomes counterparts like centromeres or telomeres might be explained exactly by this "self organization" model. It would also explain tissue-specific chromosome positioning pattern, because in different tissues prevails an expression of different genes. Interestingly it turned out that chromosome topology may be changed as a result of intranuclear irregularities. Such data were demonstrated after examining sperm cells carrying reciprocal translocations [9] or aneuploidy [10].

This study being a preliminary stage of investigation was aimed to identify changes in chromosome topology at the fragment of myogenesis from myoblasts to myogenic differentiated myotubes. Chromosome centromere topology was studied by the FISH technique and the 2D images. An aim of intranuclear chromosome positioning was brought by a comparison of two sex chromosomes (chromosomes $\mathrm{X}$ and $\mathrm{Y}$ ) and selected autosome (chromosome 4) in both types of human myogenic cells.

\section{Materials and methods}

Cell culture. Tissue samples were picked up from the human subject at the process of the ACL (Anterior Cruciate Ligament) reconstruction. The remaining (after surgery) tissue material has been accepted by both patient and the Local Bioethical Committee (Medical University of Poznań) to be used for research purposes. In every case the appropriate written consent was obtained. Isolated cells were next cultured in vitro for two weeks in Dulbecco's Modified Eagle Medium with high content of glucose (4500 $\mathrm{mg} / \mathrm{ml}$ ) and with addition of $20 \%$ FBS (Fetal Bovine Serum) and growth factors [11]. About $1 \times 10^{5}$ myoblasts were placed on glass cover slips. After covering the cover slip half of the specimen was subjected to fixation process, while the other half was intended to accomplish myoblast transformation (Fig. 1a) into myotubes (Fig. 1b). Those cells after another two-week culture in Dulbecco's Modified Eagle Medium with addition of $0.5 \%$ FBS were able to undergo fixation process.

Cell fixation and hybridization. Cells were prewashed in PBS (Phosphate Buffered Saline) ( $\mathrm{pH}$ 7.4) to remove remaining culture medium. Next, myoblasts and myotubes were fixed in 4\% PFA solution (4\% paraformaldehyde) in PBS for 10-12 minutes. To rinse out the fixative, cells were washed three times in PBS (each wash lasted for 5 minutes), then subjected to $0.5 \%$ Triton X-100 solution in PBS for 10 minutes and 20\% glycerol/PBS for 30 minutes. Afterwards, it was performed the triple freezing-thawing procedure (in liquid nitrogen) followed by 5 minutes incubation in $0.1 \mathrm{~N} \mathrm{HCl}$. At the end of fixation both myoblasts and myotubes were incubated in $50 \%$ formamide for 8 days in $4^{\circ} \mathrm{C}$.

After the eight-days incubation in formamide, cells were rinsed with $2 \times$ SSC buffer $(2 \times$ Saline-Sodium Citrate buffer $)$, dehydrated in ethanol $(70 \%, 85 \%, 96 \%)$ - three minutes each - and left to dry at the room temperature. Prewarmed probes $\left(37^{\circ} \mathrm{C}\right)$ were placed on completely dry and also prewarmed $\left(37^{\circ} \mathrm{C}\right)$ specimens and denatured at $75^{\circ} \mathrm{C}$. We used directly labeled human $\alpha$-satellite probes for X (LPE0XG), Y (LPE0YcR) and 4 (LPE04G) chromosomes (Cytocell Technologies Ltd., Cambridge UK). After overnight incubation in light proof and humidified chamber the cells were washed, first in $0.4 \times \mathrm{SSC}$ buffer in $72^{\circ} \mathrm{C}$ and then in $2 \times \mathrm{SSC}$ buffer with addition of $0.05 \%$ Tween 20 at room temperature. For counterstaining DAPI solutions (4,6-diamidino-2-phenyl-indole $\mathrm{HCl}$ ) was used. After such procedure there were no problems to discern between myoblasts and myotubes (Fig. 1).

Creation of database for centromeres of $4, X$ and $Y$ chromosomes All 2D images were created by applying fluorescent microscope BX-41 (Olympus) cooperating with ISIS Metasystems computer program. Entire measurements were performed using Image J v 1.37 computer program in pixel or (as for area calculation) in pixel $^{2}$ units. Parameters measured for chromosomes 4 as well as for chromosomes $\mathrm{X}$ and $\mathrm{Y}$ have been listed in Table 1 and in Figure 2. Apart from that it was measured (in percentage) the frequency of the centromere FISH signals in three radial zones (central, internal and peripheral) into which the observed nucleus was subdivided (Fig. 3).

Statistical analysis. For statistical evaluation of centromere FISH signals it was applied Fisher-test $(\alpha=0.05)$, one-way ANOVA test $(\alpha=0.05)$ and U Mann-Whitney test $(\alpha=0.05)$. The first test was used to describe a frequency and simultaneously the distribution of chromosome centromeres in three radial cell nuclear areas. The second and the third test were used to show statistics of spatial location of chromosome centromeres in examined cells. Statistical analysis proceeded with the use of Analyse-it for Microsoft Excel + General 1.73 .

\section{Results}

Intranuclear location of chromosomes $4, \mathrm{X}$ and $\mathrm{Y}$ centromeres was examined based on fluorescent microscope images of myoblasts and myotubes from the same individual with karyotype 46, XY.

During conducted studies it was observed statistical difference between the average myoblasts (11547.92 pixels $\left.^{2}\right)$ and myotubes (16527.34 pixels ${ }^{2}$ ) nuclear area $(\mathrm{p}<0.0001)$, however, it seemed that myoblast's nuclear shape as well as nuclear shape of myotubes remained invariable. These observations indirectly 

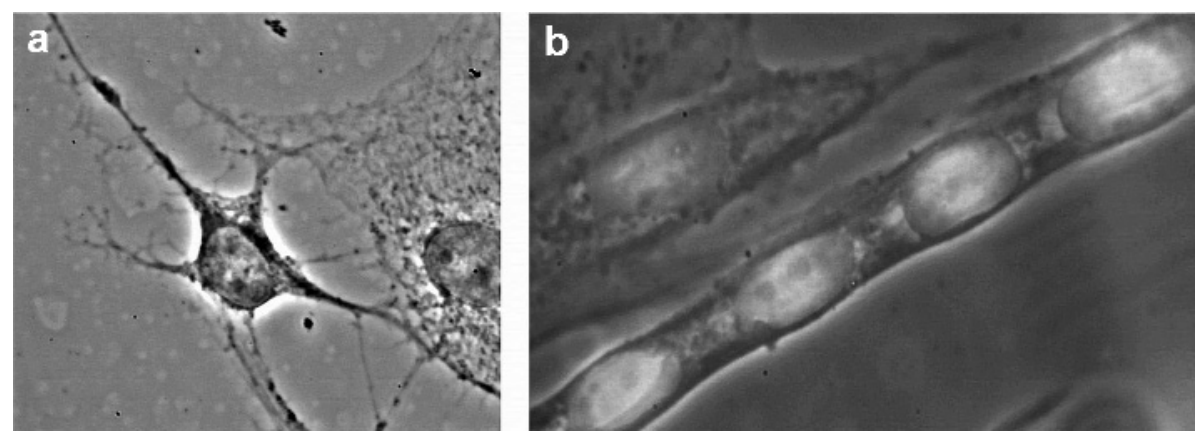

Fig. 1. Studied cell types: (a) myoblast, (b) myotube (magnification $1000 \times$ ).
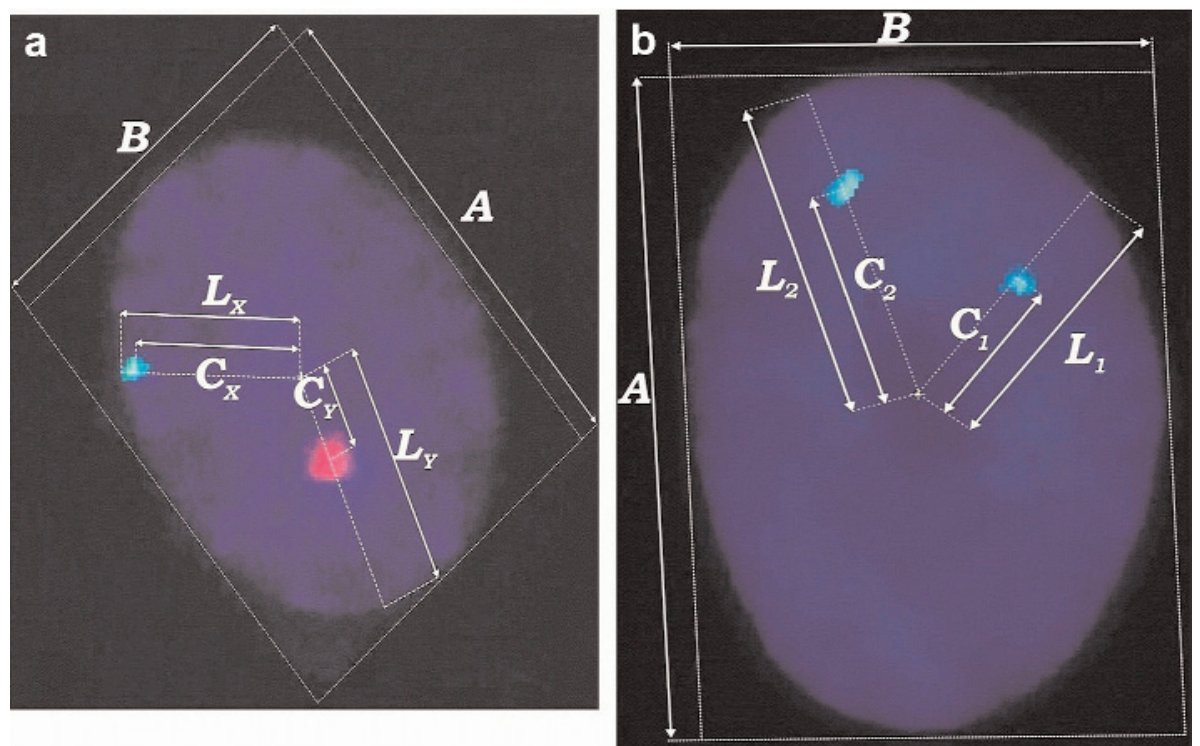

Fig. 2. Determination of the topology of chromosome centromeres in nuclei of human myoblasts. Fluorescent in situ hybridization (FISH) applying: DAPI (blue color), as a counterstain; $\alpha$-satellite probe specific for chromosome 4 and X, labeled by FITC (green color) and $\alpha$-satellite probe specific for chromosome Y, labeled by Texas red (red color). Images are two-dimensional projections (2D) from the fluorescent microscope BX 41 (Olympus). In a picture (a) are presented: a major $-\mathrm{A}$ - and minor $-\mathrm{B}-$ axis, besides also a distance from the nuclear centre of mass to the chromosome $\mathrm{X}$ centromere, FISH signal $-\mathrm{C}_{\mathrm{X}}$; distance from the nuclear centre of mass to nuclear membrane measured in a straight line going through the chromosome $\mathrm{X}$ centromere, FISH signal - $\mathrm{L}^{\mathrm{X}}$; distance from the nuclear centre of mass to chromosome $\mathrm{Y}$ centromere, FISH signal - $\mathrm{C}_{\mathrm{Y}}$; distance from the nuclear centre of mass to nuclear membrane measured in a straight line going through the chromosome $\mathrm{Y}$ centromere FISH signal $-\mathrm{L}_{\mathrm{Y}}$. In a picture (b) are presented: a major $-\mathrm{A}-$ and minor $-\mathrm{B}$ - axis, besides also a distance from the nuclear centre of mass to the closer chromosome 4 centromere, FISH signal $-\mathrm{C}_{1}$; distance from the nuclear centre of mass to nuclear membrane measured in a straight line going through the closer chromosome 4 centromere, FISH signal $-\mathrm{L}_{1}$; distance from the nuclear centre of mass to further chromosome 4 centromere, FISH signal $-\mathrm{C}_{2}$; distance from the nuclear centre of mass to nuclear membrane measured in a straight line going through the further chromosome 4 centromere, FISH signal $-\mathrm{L}_{2}$.

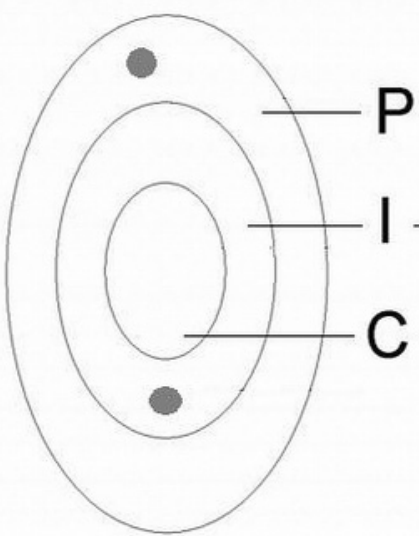

INTERNAL - PERIPHERAL

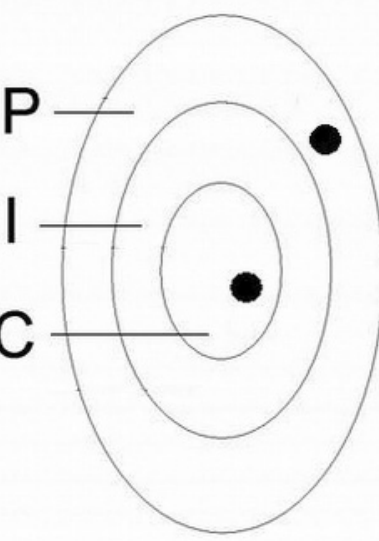

CENTRAL - PERIPHERAL
Fig. 3. Representative draft showing a simultaneous distribution of two centromeres, in three equal radial nuclear areas: peripheral $(\mathrm{P})$, internal (I) and central (C). confirmed results obtained with $\Omega$ parameter itself received as a ratio of longer to shorter nuclear axis, although $\Omega$ parameter did not demonstrate statistically significant differences between myoblasts (1.473) and myotubes (1.507) (both are presented as the average values). This data, however, allowed us to compare the nuclei of both examined cell types.

Results listed in Table 2 illustrate the chromosomes $4, \mathrm{X}$ and $\mathrm{Y}$ centromeres intranuclear location in both examined cell types. During investigations there were measured $\mathrm{C}$ and $\mathrm{L}$ parameters (Fig. 2), however the reliable information was brought by application of the observed $\mathrm{O}_{1}, \mathrm{O}_{2}, \mathrm{O}_{\mathrm{X}}$ and $\mathrm{O}_{\mathrm{Y}}$ parameters, being their ratios (see, Table 1).

The mean value $\mathrm{O}_{1}$ parameter in myotubes $(0.55)$ was statistically higher than for myoblasts $(0.49)$ $(\mathrm{p}=0.0422)$ (both are the average values), so it can be concluded that the closer centromeres of chromosomes 
Table 1. Geometric parameters used to describe intranuclear topology of chromosome centromeres.

\begin{tabular}{|c|c|c|c|}
\hline \multicolumn{2}{|l|}{ Chromosomes 4} & \multicolumn{2}{|l|}{ Chromosomes X \& Y } \\
\hline Nuclear area & $P$ & Nuclear area & $P$ \\
\hline Major axis & A & Major axis & A \\
\hline Minor axis & B & Minor axis & B \\
\hline $\mathrm{A} / \mathrm{B}$ & $\Omega$ & $\mathrm{A} / \mathrm{B}$ & $\Omega$ \\
\hline $\begin{array}{l}\text { Distance from nuclear centre of mass to closer } \\
\text { chromosome } 4 \text { centromere FISH signal }\end{array}$ & $\mathrm{C}_{1}$ & $\begin{array}{l}\text { Distance from nuclear centre of mass to chromosome } \mathrm{X} \\
\text { centromere FISH signal }\end{array}$ & $\mathrm{C}_{\mathrm{X}}$ \\
\hline $\begin{array}{l}\text { Distance from nuclear centre of mass to further } \\
\text { chromosome } 4 \text { centromere FISH signal }\end{array}$ & $\mathrm{C}_{2}$ & $\begin{array}{l}\text { Distance from nuclear centre of mass to chromosome Y } \\
\text { centromere FISH signal }\end{array}$ & $\mathrm{C}_{\mathrm{Y}}$ \\
\hline Distance between two centromere FISH signals & $\mathrm{C}_{\mathrm{M}}$ & Distance between two centromere FISH signals & $\mathrm{C}_{\mathrm{M}}$ \\
\hline $\begin{array}{l}\text { Distance from nuclear centre of mass to nuclear } \\
\text { membrane measured in a straight line going through the } \\
\text { closer chromosome } 4 \text { centromere FISH signal }\end{array}$ & $\mathrm{L}_{1}$ & $\begin{array}{l}\text { Distance from nuclear centre of mass to nuclear } \\
\text { membrane measured in a straight line going through the } \\
\text { chromosome X centromere FISH signal }\end{array}$ & $\mathrm{L}_{\mathrm{X}}$ \\
\hline $\begin{array}{l}\text { Distance from nuclear centre of mass to nuclear } \\
\text { membrane measured in a straight line going through the } \\
\text { further chromosome } 4 \text { centromere FISH signal }\end{array}$ & $\mathrm{L}_{2}$ & $\begin{array}{l}\text { Distance from nuclear centre of mass to nuclear } \\
\text { membrane measured in a straight line going through the } \\
\text { chromosome Y centromere FISH signal }\end{array}$ & $\mathrm{L}_{\mathrm{Y}}$ \\
\hline $\mathrm{C}_{1} / \mathrm{L}_{1}$ & $\mathrm{O}_{1}$ & $\mathrm{C}_{\mathrm{X}} / \mathrm{L}_{\mathrm{X}}$ & $\mathrm{O}_{\mathrm{X}}$ \\
\hline $\mathrm{C}_{2} / \mathrm{L}_{2}$ & $\mathrm{O}_{2}$ & $\mathrm{C}_{\mathrm{Y}} / \mathrm{L}_{\mathrm{Y}}$ & $\mathrm{O}_{\mathrm{Y}}$ \\
\hline
\end{tabular}

Table 2. Spatial centromere location of chromosomes 4, X and $\mathrm{Y}$ within myoblasts and myotubes nuclei. To get the meaning of parameters see, Table 1. Statistical significance between mean values was determined using a one-way analysis of variance (ANOVA) and MannWhitney $U$ test. All tests were determined at the significance level, $\mathrm{p}=0.05$.

\begin{tabular}{|c|c|c|c|c|c|c|c|}
\hline & \multicolumn{6}{|c|}{ Chromosomes 4} & \multirow{2}{*}{$\begin{array}{c}\text { Between signals } \\
\mathrm{C}_{\mathrm{M}}\end{array}$} \\
\hline & $\mathrm{C}_{1}$ & $\mathrm{~L}_{1}$ & $\mathrm{O}_{1}$ & $\mathrm{C}_{2}$ & $\mathrm{~L}_{2}$ & $\mathrm{O}_{2}$ & \\
\hline Myoblasts & 27.64 & 56.98 & $0.49^{\mathrm{a}}$ & 39.70 & 59.57 & 0.66 & $48.13^{b}$ \\
\hline SD & $\mathrm{n} / \mathrm{d}$ & $\mathrm{n} / \mathrm{d}$ & 0.19 & $\mathrm{n} / \mathrm{d}$ & $\mathrm{n} / \mathrm{d}$ & 0.17 & 22.00 \\
\hline SE & $\mathrm{n} / \mathrm{d}$ & $\mathrm{n} / \mathrm{d}$ & 0.02 & $\mathrm{n} / \mathrm{d}$ & $\mathrm{n} / \mathrm{d}$ & 0.02 & 2.55 \\
\hline Myotubes & 37.89 & 68.62 & 0.55 & 50.87 & 72.92 & 0.70 & 62.25 \\
\hline SD & $\mathrm{n} / \mathrm{d}$ & $\mathrm{n} / \mathrm{d}$ & 0.21 & $\mathrm{n} / \mathrm{d}$ & $\mathrm{n} / \mathrm{d}$ & 0.16 & 29.55 \\
\hline \multirow[t]{3}{*}{$\mathrm{SE}$} & $\mathrm{n} / \mathrm{d}$ & $\mathrm{n} / \mathrm{d}$ & 0.02 & $\mathrm{n} / \mathrm{d}$ & $\mathrm{n} / \mathrm{d}$ & 0.02 & 3.48 \\
\hline & \multicolumn{3}{|c|}{ Chromosome X } & \multicolumn{3}{|c|}{ Chromosome Y } & Between signals \\
\hline & $\mathrm{C}_{\mathrm{X}}$ & $\mathrm{L}_{\mathrm{X}}$ & $\mathrm{O}_{\mathrm{X}}$ & $\mathrm{C}_{\mathrm{Y}}$ & $\mathrm{L}_{\mathrm{Y}}$ & $\mathrm{O}_{\mathrm{Y}}$ & $\mathrm{C}_{\mathrm{M}}$ \\
\hline Myoblasts & 35.99 & 61.00 & $0.59^{\mathrm{c}}$ & 26.53 & 60.54 & $0.44^{\mathrm{d}}$ & $45.94^{\mathrm{e}}$ \\
\hline SD & $\mathrm{n} / \mathrm{d}$ & $\mathrm{n} / \mathrm{d}$ & 0.20 & $\mathrm{n} / \mathrm{d}$ & $\mathrm{n} / \mathrm{d}$ & 0.19 & 21.37 \\
\hline SE & $\mathrm{n} / \mathrm{d}$ & $\mathrm{n} / \mathrm{d}$ & 0.02 & $\mathrm{n} / \mathrm{d}$ & $\mathrm{n} / \mathrm{d}$ & 0.02 & 2.44 \\
\hline Myotubes & 48.32 & 71.59 & 0.67 & 24.59 & 71.14 & 0.36 & 56.89 \\
\hline $\mathrm{SD}$ & $\mathrm{n} / \mathrm{d}$ & $\mathrm{n} / \mathrm{d}$ & 0.21 & $\mathrm{n} / \mathrm{d}$ & $\mathrm{n} / \mathrm{d}$ & 0.24 & 25.19 \\
\hline SE & $\mathrm{n} / \mathrm{d}$ & $\mathrm{n} / \mathrm{d}$ & 0.02 & $\mathrm{n} / \mathrm{d}$ & $\mathrm{n} / \mathrm{d}$ & 0.03 & 2.87 \\
\hline
\end{tabular}

$\mathrm{n} / \mathrm{d}$ - not done

$\mathrm{a}$ - result statistically significant in comparison to myotubes $[\mathrm{p}=0.0422]$

$\mathrm{b}$ - result statistically significant in comparison to myotubes $[\mathrm{p}=0.0067]$

c - result statistically significant in comparison to myotubes $[\mathrm{p}=0.0035]$

$\mathrm{d}$ - result statistically significant in comparison to myotubes $[\mathrm{p}=0.0020]$

$\mathrm{e}$ - result statistically significant in comparison to myotubes $[\mathrm{p}=0.0003]$ 
Table 3. Radial centromere distribution of chromosomes 4, X and Y in three nuclear areas (P-peripheral, I-internal, C-central) observed in myoblasts and myotubes. Statistical significance was determined using Fisher's test.

\begin{tabular}{|c|c|c|c|c|c|c|c|c|c|}
\hline \multirow{3}{*}{ Cell type } & \multicolumn{3}{|c|}{ Chromosomes 4} & \multicolumn{3}{|c|}{ Chromosome X } & \multicolumn{3}{|c|}{ Chromosome Y } \\
\hline & \multicolumn{9}{|c|}{ nuclear area } \\
\hline & $\mathrm{C}$ & I & $\mathrm{P}$ & $\mathrm{C}$ & $\mathrm{I}^{\mathrm{a}}$ & $\mathrm{P}^{\mathrm{a}}$ & $\mathrm{C}^{\mathrm{b}}$ & $\mathrm{I}^{\mathrm{b}}$ & $\mathrm{P}$ \\
\hline Myoblasts [\%] & 9 & 59 & 32 & 13 & 39 & 48 & 26 & 60 & 14 \\
\hline Myotubes [\%] & 9 & 49 & 42 & 9 & 23 & 68 & 59 & 27 & 14 \\
\hline
\end{tabular}

a - result statistically significant in comparison to internal position of chromosome $\mathrm{X}$ centromere in examined cell types nuclei [p=0.0007]

$\mathrm{b}$ - result statistically significant in comparison to central position of chromosome $\mathrm{Y}$ centromere in examined cell types nuclei [p $<0.0001]$

Table 4. Simultaneous radial centromere distribution of chromosomes 4, X and $\mathrm{Y}$ in three nuclear areas (P-peripheral, I-internal, $\mathrm{C}$-central) observed in myoblasts and myotubes nuclei. Possible combinations of centromeres location are: CC- central-central; CIcentral-internal; CP- central-peripheral; II- internal-internal; IPinternal-peripheral; PP- peripheral-peripheral. Statistical significance was determined using Fisher's test.

\begin{tabular}{|l|c|c|c|c|c|c|}
\hline & \multicolumn{7}{|c|}{ Nuclear area } \\
\hline Cell type & $\mathrm{CC}$ & $\mathrm{CI}$ & $\mathrm{CP}$ & II $^{\text {a }}$ & IP $^{\mathrm{a}}$ & PP \\
\hline Myoblasts [\%] & 1 & 8 & 7 & 42 & 27 & 15 \\
\hline Myotubes [\%] & 0 & 8 & 10 & 24 & 43 & 15 \\
\hline \multicolumn{7}{|c|}{ Chromosomes X \& Y } \\
\hline Cell type & $\mathrm{CC}$ & $\mathrm{CI}$ & $\mathrm{CP}^{\mathrm{b}}$ & II $^{\mathrm{b}}$ & IP & PP \\
\hline Myoblasts [\%] & 1 & 19 & 9 & 14 & 29 & 5 \\
\hline Myotubes [\%] & 4 & 13 & 31 & 3 & 20 & 6 \\
\hline
\end{tabular}

a,b- Superscript letters assign statistically significant differences in $[\mathrm{p}<0.05]$

4 were found nearer to the nuclear rim in myotubes than in myoblasts. Whereas more distant centromeres of chromosomes 4 did not demonstrate any location changes in both examined cell types $\left(\mathrm{O}_{2}\right.$ were statistically insignificant). Interestingly, the mean value of $\mathrm{O}_{\mathrm{X}}$ parameter showed the statistically significant difference between myoblasts $(0.59)$ and myotubes $(0.67)$ $(p=0.0035)$. Statistically higher $\mathrm{O}_{X}$ value revealed in myotubes than in myoblasts suggests that chromosome $\mathrm{X}$ centromeres have been found closer to the nuclear membrane in myotubes than in myoblasts. Statistically significant differences were also found between myoblasts and myotubes concerning $\mathrm{O}_{\mathrm{Y}}$ parameter $(0.44$ and 0.36 respectively; $(p=0.002)$. Statistically lower result obtained for myotubes (than for myoblasts) concerning $\mathrm{Y}$ chromosome showed that this centromere was closer to the nuclear centre in myotubes than in myoblasts. Interestingly, statistically significant differences were also found in a distance between chromosome X (48.13) and Y (62.13) cen- tromeres, as well as between pair of chromosomes 4 centromeres (45.94 and 56.89). In the first case statistical significance was $\mathrm{p}=0.0067$ while in the second $\mathrm{p}=0.0003$.

In Table 3 are presented results obtained for chromosomes $4, \mathrm{X}$ and $\mathrm{Y}$ centromeres frequency in three observed radial nuclear areas ( $\mathrm{P}$ - peripheral, I - internal, C - central) (Fig. 3). The statistically significant differences were observed only in two cases, First, it was observed difference between peripheral and internal position of chromosome $\mathrm{X}$ centromeres in respect to the examined cell types, $\mathrm{p}=0.0007$. Peripheral localization of chromosome $\mathrm{X}$ centromers was found more often in myotubes comparing to myoblasts. Second statistically significant difference was noted between internal and central position of $\mathrm{Y}$ chromosome centromeres $(\mathrm{p}<0.0001)$, but these data indicate that myotubes in contrast to myoblasts have more centromeres of the $\mathrm{Y}$ chromosome contained in a central part of the nucleus.

Results presented in Table 4 demonstrated the simultaneous distribution of the pair of chromosomes 4 centromeres, as well as distribution of chromosomes $\mathrm{X}$ and $\mathrm{Y}$ centromeres in myoblasts and myotubes (Fig. 3). During investigations of chromosomes 4 centromeres distribution, a statistically significant differences were only found between internal-internal and internal-peripheral positions, $(\mathrm{p}<0.05)$. These results indicated that in myotubes were found more nuclei with internal-peripheral position of homologous chromosome 4 centromeres while in myoblasts were more internal-internal positions of chromosome 4 centromeres. Differences were also found at analysis of chromosomes $\mathrm{X}$ and $\mathrm{Y}$ centromeres distribution. Statistically significant differences were observed between central-peripheral and internal-internal locations of both examined chromosome centromeres, $(p<0.05)$. These results indicated that in myoblasts were found significantly more nuclei with internalinternal position of chromosome $\mathrm{X}$ and $\mathrm{Y}$ centromeres than in myotubes while in myotubes were found significantly more nuclei with central-peripheral position. Presented differences show the extent of spread ten- 
dency for $\mathrm{X}$ and $\mathrm{Y}$ chromosome centromeres, where the first of them allocated at nuclear periphery and the second in the centre of nucleus at the process of myogenic cells differentiation.

\section{Discussion}

During the performed series of observations with myoblasts and myotubes, the changes in centromeres topology were visible in all cases of the examined chromosomes. It could be inferred, that analysis of chromosome topology connected with the cells pathway along myogenesis, could be a logical and important topic for research on stem cells differentiation. It seems that changes in topology connected with cell differentiation may also involve centromeres heterochromatin. Probably, the spatial centromere heterochromatin organization can be also an important epigenetic regulatory mechanism of gene enhancement [2] or silencing [12,13].

The obtained results revealed that during myoblastmyotube differentiation the chromosome $\mathrm{X}$ centromeres translocated into nuclear periphery, similarly as one of the centromeres of chromosome 4. At the moment we are not able to say if such relocation is a random phenomenon or whether it depends on parental origin of chromosome 4. Further studies would be required to have it clarified co-hybridizing the test probe with probe specific for a $\mathrm{CNV}$ in the chromosome of known parental origin. During the cell differentiation, we also observed a tendency for relocation of chromosome Y centromere to the centre of nucleus. Similar results concerning the $\mathrm{Y}$ chromosome CT's were previously observed by Cremer and co-workers [14]. After analysis of the CT's rearrangement in flat-ellipsoid nuclei of diploid amniotic fluid cells and fibroblasts they have noticed that all the studied small chromosomes including the $\mathrm{CT}$ of chromosome $\mathrm{Y}$ were located near the centre of nucleus whereas the large chromosomes like chromosomes 4 and $\mathrm{X}$ were preferentially located in the vicinity of the nuclear membrane. Slightly different results were obtained [14] during analysis of spherical lymphocytes nuclei. In this case it was noticed a central location for the small, gene-dense chromosomes, however, small but gene-poor chromosomes like chromosome $\mathrm{Y}$ and large chromosomes like chromosomes 4 and $\mathrm{X}$ were localized near nuclear periphery.

One of the first observations regarding the chromosome topology at myogenesis was presented in 1996 by Chaly and Munro [15]. They indicated tendency for centromere reposition towards the nuclear periphery in L6E9 rat cell line. Interesting information connected with the differentiation process can be also extracted from study by Bártová [2]. During her investigations of human undifferentiated leukaemic HL-60 cells and terminally differentiated human granulocytes, it was observed that centromeres of chromosomes 8 and 13 were localized more centrally inside CT's than studied expressed genes: $A B L, c-M Y C$ and RB1 [2]. Differentiation process and chromosome topology were also investigated using developing adipocytes [6]. There were not clearly shown statistically significant differences between the examined positions of territories of chromosomes 12 and 16. However mean value of the total radial distribution presented a tendency to shift CT 16 to nuclear center while CT 12 to peripheral nuclear zone. All these results reassure our data concerning the chromosomes migration at cell differentiation.

The chromosome topology was examined not only in humans or rodents. Recent reports showed the chromosomes rearrangement in e.g. Arabidopsis thaliana [16] or Xaenopus laevis [17]. Interesting results were provided by Stadler and co-workers [18] which showed positions of chicken chromosomes 1 and 8 at the developmental pathways from multipotent myeloid precursor cells to activated macrophages. Observations from this study are in close agreement with ours since the studied chicken chromosome 1 is comparable in length to human chromosome 4 investigated in our experiments. In bacterial lipopolysaccharide (LPS) - stimulated macrophages, CTs 1 were found closer to the nuclear rim than in proerythroblasts, myeloblasts and in multipotent myeloid precursor cells. Chromosome 8 did not exhibit any significant location changes during the cell differentiation process. It was also noticed that CTs 1 were located more peripherally than CTs 8 in multipotent myeloid precursor cells as well as in proerythroblasts. Interestingly, some other phenomena have been observed. In Alcobia and co-workers study, it was noted that centromeres approached closer to themselves and started creating clusters called chromocenters [19]. Interestingly, centromeres' clustering was also observed while muscle cells differentiated [20]. Probably increased level of $\mathrm{CpG}$ islands methylating protein as well as DNA metylation in pericentromeric regions influenced the formation of chromocenters [21].

\section{Conclusions}

All the results obtained indicate that in the cell nuclei during the differentiation process can be found important changes in chromosome centromere topology. Probably those changes may influence chromatin function and cell developmental pathway. Chromosome centromere topology can be considered as a critical cognitive tool to define these cells at certain developmental stage. Therefore chronological changes in chromosomes topology may be helpful at discrimination of further stem cells subpopulations, unrevealed so far, at different stages of myogenesis.

Acknowledgments: Authors wish to thank Polish Ministry of Sciences and Education for generous sponsoring of the study. 


\section{References}

[ 1] Amrichova J, Lukasowa E, Kozubek S, Kozubek M. Nuclear and territorial topography of chromosome telomeres in human lymphocytes. Exp. Cell. Res. 2003;289:11-26.

[2] Bártová E, Kozubek S, Jirsova P, et al. Nuclear structure and gene activity in human differentiated cells. J. Structural. Biol. 2002;139:76-89.

[ 3] Ukekawa R, Maegawa N, Mizutani E, Fujii M, Ayusawa D. Proteasome inhibitors induce changes in chromatin structure characteristic of senescent human fibroblasts. Biosci. Biotechnol. Biochem. 2004;68:2395-2397.

[4] Schöfer C, Weipoltshammer K. Gene dynamics and nuclear architecture during differentiation. Differentiation 2008;76:41-56.

[ 5] Galiová G, Bártová E, Kozubek S. Nuclear topography of $\beta$ like globin gene cluster in IL-3-stimulated human leukemic K-562 cells. Blood Cells Mol Dis 2004;33:4 -14.

[6] Kuroda M, Tanabe H, Yoshida K. Alteration of chromosome positioning during adipocyte differentiation. J. Cell. Sci. 2004 ;117:5897-5903.

[ 7] Morey C, Da Silva NR, Perry P, Bickmore WA. Nuclear reorganisation and chromatin decondensation are conserved, but distinct, mechanisms linked to Hox gene activation. Development 2007;134:909-919.

[8] Wiblin AE, Cui W, Clark JA, Bickmore WA. Distinctive nuclear organization of centromeres and regions involved in pluripotency in human embryonic stem cells. J. Cell. Sci. 2005;118:3861-3868.

[9] Wiland E, Zegalo M, Kurpisz M. Interindividual differences and alternations in the topology of chromosomes in human sperm nuclei of fertile donors and carriers of reciprocal translocations. Chromosome. Res. 2008;16:291-305.

[10] Olszewska M, Wiland E, Kurpisz, M. Positioning of chromosome 15, 18, X and Y centromeres in sperm cells of fertile individuals and infertile patients with increased level of aneuploidy. Chromosome Res: (on-line first) (2008).

[11] Rozwadowska N, Fiszer D, Siminiak T, Kalawski R, Kurpisz M. Evaluation of in vitro culture of human myoblasts for tissue autotransplants to the post - infarcted hart. Pol Heart J. 2002;57:223-237.
[12] Brown KE, Guest SS, Smale ST, Hahm K, Merkenschlager M, Fisher AG. Association of transcriptionally silent genes with Ikaros complexes at centromeric heterochromatin. Cell 1997;91:845-854.

[13] Brown KE, Baxter J, Graf D, Merkenschlager M, Fisher AG. Dynamic repositioning of genes in the nucleus of lymphocytes preparing for cell division. Mol Cell. 1999;3:207-217.

[14] Cremer T, Cremer C. Chromosome territories, nuclear architecture and gene regulation in mammalian cells. Nat Rev Genet. 2001;2:292-301.

[15] Chaly N, Munro SB. Centromeres reposition to the nuclear periphery during L6E9 myogenesis in vitro. Exp Cell Res. 1996;223:274-278.

[16] Berr A, Schubert I. Interphase chromosome arrangement in Arabidopsis thaliana is similar in differentiated and meristematic tissues and shows a transient mirror symmetry after nuclear division. Genetics 2007;176:853-863.

[17] König P, Braunfeld MB, Sedat JW, Agard DA. The threedimensional structure of in vitro reconstituted Xenopus laevis chromosomes by EM tomography. Chromosoma 2007;116:349-372.

[18] Stadler S, Schnapp V, Mayer R, et al. The architecture of chicken chromosome territories changes during differentiation. BMC Cell Biol. 2004;5:44.

[19] Alcobia I, Quina AS, Neves H, Clode N, Parreira L. The spatial organization of centromeric heterochromatin during normal human lymphopoiesis evidence for ontogenically determined spatial patterns. Exp Cell Res. 2003;290:358-369.

[20] Terranova R, Sauer S, Merkenschlager M, Fisher AG. The reorganisation of constitutive heterochromatin in differentiating muscle requires HDAC activity. Exp Cell Res. 2005;310:344 -356.

[21] Brero A, Easwaran HP, Nowak D. Methyl CpG-binding proteins induce large-scale chromatin reorganization during terminal differentiation. $J$ Cell Biol. 2005;169:733-743.

Submitted: 11 April, 2009 Accepted after reviews: 6 July, 2009 